\title{
Review of systematic reviews on acute procedural pain in children in the hospital setting
}

\author{
Jennifer Stinson RN PhD CPNP ${ }^{1}$, Janet Yamada RN MSc PhD (student) ${ }^{2}$, Alison Dickson BSc MSc BSc Pharm (student) ${ }^{2}$, \\ Jasmine Lamba BSc $(\text { Hon })^{2}$, Bonnie Stevens RN PhD 3
}

\begin{abstract}
J Stinson, J Yamada, A Dickson, J Lamba, B Stevens. Review of systematic reviews on acute procedural pain in children in the hospital setting. Pain Res Manage 2008;13(1):51-57.
\end{abstract}

BACKGROUND: Acute pain is a common experience for hospitalized children. Despite mounting research on treatments for acute procedure-related pain, it remains inadequately treated.

OBJECTIVE: To critically appraise all systematic reviews on the effectiveness of acute procedure-related pain management in hospitalized children.

METHODS: Published systematic reviews and meta-analyses on pharmacological and nonpharmacological management of acute procedure-related pain in hospitalized children aged one to 18 years were evaluated. Electronic searches were conducted in the Cochrane Database of Systematic Reviews, Medline, EMBASE, the Cumulative Index to Nursing and Allied Health Literature and PsycINFO. Two reviewers independently selected articles for review and assessed their quality using a validated seven-point quality assessment measure. Any disagreements were resolved by a third reviewer. RESULTS: Of 1469 published articles on interventions for acute pain in hospitalized children, eight systematic reviews met the inclusion criteria and were included in the analysis. However, only five of these reviews were of high quality. Critical appraisal of pharmacological pain interventions indicated that amethocaine was superior to EMLA (AstraZeneca Canada Inc) for reducing needle pain. Distraction and hypnosis were nonpharmacological interventions effective for management of acute procedure-related pain in hospitalized children.

CONCLUSIONS: There is growing evidence of rigorous evaluations of both pharmacological and nonpharmacological strategies for acute procedure-related pain in children; however, the evidence underlying some commonly used strategies is limited. The present review will enable the creation of a future research plan to facilitate clinical decision making and to develop clinical policy for managing acute procedure-related pain in children.

Key Words: Acute pain, Children; Pain management; Systematic review

\section{Un examen d'analyses systématiques sur la douleur aiguë causée par des interventions chez les enfants hospitalisés}

HISTORIQUE : Il est courant que les enfants hospitalisés souffrent de douleur aiguë. Malgré les données croissantes sur le traitement de la douleur aiguë causée par des interventions, ce type de douleur demeure mal traité

OBJECTIF : Procéder à l'évaluation critique de toutes les analyses systématiques sur l'efficacité de la prise en charge de la douleur aiguë reliée aux interventions chez les enfants hospitalisés.

MÉTHODOLOGIE : Les auteurs ont évalué les analyses systématiques publiées et les méta-analyses sur la prise en charge pharmacologique et non pharmacologique de la douleur aiguë reliée aux interventions chez les enfants hospitalisés de un à 18 ans. Ils ont effectué des recherches électroniques dans la Cochrane Database of Systematic Review, Medline, EMBASE, le Cumulative Index to Nursing and Allied Health Literature et PsyhINFO. Deux évaluateurs ont sélectionné de manière indépendante les articles à examiner et en ont déterminé la qualité au moyen d'une mesure validée d'évaluation de la qualité de sept points. Un troisième évaluateur a tranché tout différend.

RÉSULTATS : Des 1469 articles publiés sur des interventions reliées à la douleur aiguë chez les enfants hospitalisés, huit analyses systématiques respectaient les critères d'inclusion et ont été intégrées à l'analyse. Cependant, seulement cinq de ces analyses étaient de haute qualité. D'après l'évaluation critique des interventions pharmacologiques pour la douleur aiguë, l'améthocaïne était supérieure à l'EMLA (AstraZeneca Canada Inc.) pour réduire la douleur reliée aux injections. La distraction et l'hypnose étaient des interventions non pharmacologiques efficaces pour prendre en charge la douleur aiguë reliée aux interventions chez les enfants.

CONCLUSIONS : Les données probantes augmentent sur des évaluations rigoureuses de stratégies pharmacologiques et non pharmacologiques pour soulager la douleur aiguë reliée à une intervention chez les enfants. Cependant, les données probantes relatives à certaines stratégies courantes sont limitées. La présente analyse permettra de créer un futur plan de recherche pour faciliter la prise de décision clinique et élaborer une politique clinique de prise en charge de la douleur aiguë reliée aux interventions chez les enfants.

${ }^{1}$ Lawrence S Bloomberg Faculty of Nursing, University of Toronto, Centre for Nursing and Department of Anesthesia, The Hospital for Sick Children, Toronto, Ontario; ${ }^{2}$ Centre for Nursing and Research Institute, The Hospital for Sick Children, Toronto, Ontario; ${ }^{3}$ Lawrence S Bloomberg Faculty of Nursing and Faculty of Medicine, University of Toronto, Centre for Nursing and Research Institute, Hospital for Sick Children, Toronto, Ontario

Correspondence: Dr Jennifer Stinson, Child Health Evaluative Sciences, Research Institute, The Hospital for Sick Children, 555 University Avenue, Toronto, Ontario M5G 1X8. Telephone 416-813-7654 ext 4514, fax 416-813-2143, e-mail jennifer.stinson@sickkids.ca 
$\mathrm{H}$ ospitalized children undergo multiple painful procedures; venipuncture, intravenous cannulation, capillary stick, and injections are most commonly performed (1). Procedure-related pain is also associated with a wide variety of medical treatments such as burn dressings, laser treatments for port-wine stains and suturing of lacerations. Over the past 10 to 15 years, the findings of several epidemiological surveys have consistently emphasized that a significant proportion (49\% to $64 \%$ ) of hospitalized children receive inadequate pain management despite the increase in knowledge and available treatments (2-4). In addition to undue pain and suffering, stress associated with painful procedures can influence physiological, social and cognitive outcomes (5) and have emotional and psychological implications for children and families $(6,7)$.

There has been a plethora of research on acute pediatric pain in the past decade, which has resulted in the development of multiple pediatric pain standards and guidelines (8-11). Despite these efforts, research on acute procedure-related pain in hospitalized children is not effectively translated into clinical practice. High-quality systematic reviews of trials evaluating pharmacological and nonpharmacological pain-relieving strategies can delineate the most effective ways to manage acute procedural pain in hospitalized children. As well, they can help in the development of guidelines and standards, decision-making and agendas for future research. Although many systematic reviews of individual pain management strategies exist for procedural pain, there are no rigorous evaluations of these reviews using validated quality assessment tools. Therefore, the present study aims to provide a structured review of published research evidence from systematic reviews of acute procedure-related pain management strategies in hospitalized children using a validated quality assessment evaluation measure.

\section{METHODS}

\section{Data sources}

Electronic searches were conducted by library information specialists familiar with the field. The Cochrane Database of Systematic Reviews, Medline (1966 to May 2006), EMBASE (1980 to May 2006), Cumulative Index to Nursing and Allied Health Literature (1982 to May 2006) and PsycINFO (1985 to 2006) were searched. Subject headings and MeSH terms included 'pain', 'pain measurement' and 'pain assessment'. Because the present review was part of a more comprehensive evaluation that included infant pain management strategies, key words and abbreviations used included 'infant', 'bab', 'baby', 'babies', 'neonate', 'newborn', 'premature', 'preemie', 'pediatric', 'paediatric' and 'child'. Other keywords (eg, 'meta analysis', 'systematic review', 'system review') were used to search for the ideal publication type. All search titles and abstracts were independently rated for relevance by two reviewers (JL, AD). To establish reliability of article selection between reviewers, each reviewer pilot-tested 10 review articles using the study selection criteria outlined above. There was $97 \%$ agreement on use of the selected review articles. All reviewers were blind to the names of the authors and journals. References from all systematic and meta-analytic reviews were also screened, because they were already based on exhaustive systematic searches. Only published reviews in English were included due to additional costs related to translation.

\section{Study selection}

A review was included if it reported on pharmacological and/or nonpharmacological pain management strategies for the relief of acute procedure-related pain in hospitalized children aged one to 18 years. Pain intensity was the primary outcome measure. Evaluations comprised of randomized controlled trials (RCTs), repeated measures (interrupted time series), and crossover and phase lag study designs. Both quantitative metaanalyses and qualitative systematic reviews - where the results of primary studies were not pooled statistically (12) - were also included.

\section{Data extraction}

Data were extracted from the systematic reviews and then rated for methodological quality. Raters independently extracted the year of publication, journal of publication, study participants, study focus (ie, type of pain interventions) and results from each systematic review. The summaries of the main results regarding effects on pain intensity were based on the text in the original manuscript, and focused on quantitative summaries when available. There are few well-validated tools available to rate the methodological quality of studies and/or systematic reviews. The tool developed by Oxman and Guyatt $(13,14)$ was chosen because of its well-established validity (13). Methodological quality of the systematic review was rated on a seven-point scale where a score of one (lowest) signifies extensive methodological flaws and a score of seven (highest) is indicative of minimal flaws $(13,15)$. Before rating the reviews, the quality assessment measure was pilot tested on 10 systematic reviews by two authors (JY, JS). The two reviewers independently assessed the methodological quality of the review using this quality assessment measure. There was $92 \%$ agreement between the two reviewers. Any disagreements in ratings were resolved by a third reviewer for both relevance and quality testing (BS).

\section{Data synthesis}

When available, the present study reported on effects in terms of mean effect size, standardized mean difference, relative risk and number needed to treat (NNT). If a meta-analysis had been performed, the present study also recorded whether the effect was significant or not significant. If quantitative summary measures of effectiveness were not used, the range of effects across studies was reported. If this information was not available, the author's main qualitative conclusions were reported.

\section{Description of studies}

\section{RESULTS}

A total of 1469 articles were identified from the electronic searches. Of these, 166 articles were selected for further consideration. Thirty articles were removed after accounting for duplicates $(n=22)$ or if published in languages other than English $(n=8)$. Of the 136 articles, 52 articles involved only infants and were excluded from the review whereas two articles included both infants and children. From the 84 remaining articles, a further 39 reviews were either not systematic reviews $(n=27)$ or were protocols of systematic reviews $(n=12)$. Thirtyseven articles were excluded based on the study inclusion criteria, leaving eight systematic reviews for assessment and rating (16-23) as outlined in Figure 1. Three of the reviews rated were Cochrane reviews $(16,18,22)$ while the remaining 
five were published in a variety of peer-reviewed journals $(17,19-21,23)$. Those interested in a list of the excluded articles can contact the primary author.

\section{Methodological quality of studies}

Using the scoring method outlined by Oxman and Guyatt $(13,14)$ and Jadad and McQuay $(15)$, the mean \pm SD score for the eight reviews was $5.38 \pm 1.30$ out of 7.00 . The minimum score was 4 out of 7 and the maximum score was 7 out of 7 as outlined in Tables 1 and 2. All three of the Cochrane reviews scored 7 out of 7 . Two of the remaining reviews were rated as having either minimal or minor flaws (ie, score of 5 or greater). Only one of the five most highly rated reviews addressed the effectiveness of pharmacological pain interventions (13), while the other four were based on nonpharmacological interventions. Of the remaining three reviews with major methodological flaws (score of 4 or less), two focused on pharmacological pain interventions, while one evaluated nonpharmacological interventions (Table 3). The reviews with lower scores for methodological quality did not use optimal procedures for data extraction or data analysis. Furthermore, their information on important contextual factors was very limited (ie, age, type of painful procedure). Only the five reviews with minimal to minor flaws are reviewed in more detail below.

\section{Pharmacological pain interventions}

Three reviews focused on pharmacological interventions; only one was of strong methodological quality. A summary of this highly rated review (18) is outlined in Table 1. Lander et al (18) compared two topical anesthetics, amethocaine and EMLA (AstraZeneca Canada Inc), in terms of anesthetic efficacy, ease of needle insertion and adverse events when used for intravenous cannulation and venipuncture. There were six RCTs enrolling a total of 534 children in this review. In the meta-analysis, amethocaine was determined to be superior to EMLA for reducing overall needle insertion pain, short or long application times, manufacturer recommended times and whether pain was rated using child self-report or by direct observation. The efficacy of amethocaine compared with EMLA could not be determined for venipuncture because the studies did not analyze venipuncture separately from intravenous cannulation. In addition, there was inconclusive evidence with respect to ease of needle insertion (number of needle sticks) because this outcome was not commonly reported. It is important to note that two of the lower quality rated reviews excluded from the review found amethocaine and EMLA to be equally efficacious $(20,21)$. Limitations of these reviews related to the poor quality of measurements in the included studies (ie, use of measures without demonstrated reliability and validity) and problems with double blinding of the intervention (ie, local anesthetics had different application durations).

\section{Nonpharmacological pain interventions}

Five reviews focused on nonpharmacological interventions; four were of strong methodological quality (Table 2). Richardson et al (19) evaluated the effect of hypnosis for procedural pain and distress in children with cancer. One systematic review, seven RCTs and one non-RCT were included in the review. Hypnosis resulted in statistically significant reductions in pain. However, a meta-analysis was not conducted due to variation in the population (types of cancer) and the

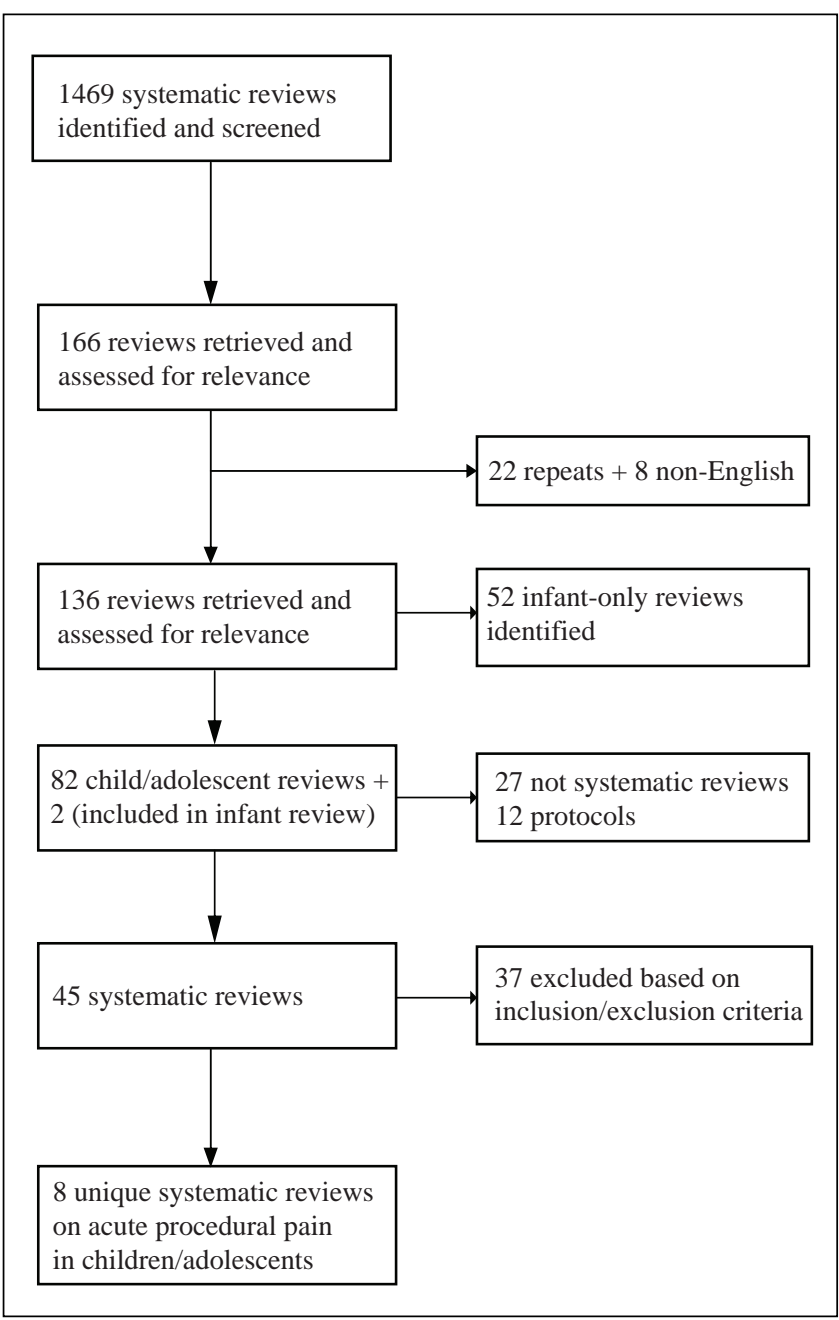

Figure 1) Study selection

interventions used. In addition, several methodological quality limitations of these studies were identified, including small sample sizes and poor reporting of key aspects of the RCTs as outlined in the Consolidated Standards of Reporting Trials (24). The authors concluded that further research was required to examine the use of hypnosis as a pharmacological adjuvant or in preparation for anesthesia; the difference between self and therapist-administered hypnosis; and the contribution of age, development and sex on the efficacy of hypnosis.

Cepeda et al (16) systematically reviewed the efficacy of music on acute, chronic and cancer pain in children and adults in 51 RCTs. Eight of the studies specifically evaluated the effect of music on pain in children (including neonates). A total of 334 children were exposed to music, and 296 acted as controls. The methodological quality of the pediatric reviews was low compared with that of the adult studies. Of the eight pediatric studies, four addressed reducing pain in neonates and were excluded. The four articles that reported on children focused on music to relieve procedural pain. Three of these studies reported clinical outcomes using quantitative data (ie, pain scores and $50 \%$ pain relief). However, the authors were not able to pool these data due to the diverse methods used to assess pain in this population. Moreover, the effectiveness of music in children based on this subset of studies was inconclusive. While listening 
TABLE 1

Systematic reviews of pharmacological interventions

\begin{tabular}{|c|c|c|c|}
\hline $\begin{array}{l}\text { Reference, } \\
\text { number of studies }\end{array}$ & $\begin{array}{l}\text { Quality } \\
\text { score }\end{array}$ & Focus & Main results \\
\hline \multirow[t]{4}{*}{$\begin{array}{l}\text { Lander et al } \\
\qquad 2006 \text { (18), } n=6\end{array}$} & 7 & $\begin{array}{l}\text { Amethocaine compared with EMLA* for needle } \\
\text { insertion procedures (venipuncture and } \\
\text { intravenous cannulation) }\end{array}$ & $\begin{array}{l}\text { Amethocaine significantly reduced self-reported pain (RR } 0.63 \text {, } \\
95 \% \mathrm{Cl} 0.45 \text { to } 0.87, \mathrm{NNT}=5) \text {, pain observed by researchers } \\
\text { (RR } 0.70,95 \% \mathrm{Cl} 0.52 \text { to } 0.96, \mathrm{NNT}=8 \text { ) and pain data combined } \\
\text { into a common pain metric (RR } 0.78,95 \% \mathrm{Cl} 0.62 \text { to } 0.98 \\
\text { NNT=15) compared with EMLA*. }\end{array}$ \\
\hline & & & $\begin{array}{l}\text { Amethocaine significantly reduced risk of pain when applied for } \\
30 \text { min to } 60 \text { min (RR } 0.61,95 \% \mathrm{Cl} 0.41 \text { to } 0.91, \mathrm{NNT}=5 \text { ), accord- } \\
\text { ing to the manufacturers' instructions (RR } 0.64,95 \% \mathrm{Cl} 0.46 \text { to } \\
0.89, \mathrm{NNT}=8 \text { ) and for }>60 \text { min (RR } 0.70,95 \% \mathrm{Cl} 0.51 \text { to } 0.96 \text {, } \\
\text { NNT=8) compared with EMLA*. }\end{array}$ \\
\hline & & & $\begin{array}{l}\text { In subgroup analysis, amethocaine was significantly more efficacious } \\
\text { in reducing pain for intravenous cannulaton (RR } 0.70,95 \% \mathrm{Cl} 0.55 \\
\text { to } 0.88, \mathrm{NNT}=7 \text { ) compared with EMLA*. }\end{array}$ \\
\hline & & & $\begin{array}{l}\text { Amethocaine was associated with significantly greater erythema } \\
\text { compared with EMLA* (RR } 14.83 ; 95 \% \mathrm{Cl} 2.28 \text { to } 96.36) \text {. EMLA* } \\
\text { was associated with blanching of the skin. }\end{array}$ \\
\hline
\end{tabular}

*AstraZeneca Canada Inc. NNT Number needed to treat

TABLE 2

Systematic reviews of nonpharmacological interventions

\begin{tabular}{lcl}
$\begin{array}{l}\text { Reference, } \\
\text { number of } \\
\text { studies }\end{array}$ & $\begin{array}{c}\text { Quality } \\
\text { score }\end{array}$ & Focus \\
\hline $\begin{array}{c}\text { Cepeda et al } \\
2006(16), \mathrm{n}=4\end{array}$ & 7 & $\begin{array}{r}\text { Music on pain during procedures } \\
\text { (intravenous cannulation and vaccination) }\end{array}$
\end{tabular}

Main results

One study reported the control group had less pain than the music group, one study found no difference between the music and control group, one study reported that the music group had less pain than the control and the fourth study's results were not reported. Therefore, there is inconclusive evidence of the effectiveness of music. Adverse events were not reported.

Kleiber and Harper 5 1999 (17), $n=10$

Richardson et al 6 2006 (18), $n=8$

Uman et al 7

$2006(22), n=28$
Distraction on pain during medical procedures (ie, IV insertion, LP, BMA, venipuncture, injection, burn treatment, dental procedure)

6 Hypnosis in pediatric cancer patients for procedure-related pain (ie, LP, BMA, venipuncture, Infusapost access)

Psychological interventions for needle-related procedural pain (ie, immunizations, venipuncture, LP, IV insertions, BMA, IM injections)
Reduced self-reported pain compared with control $(M E S=0.62)$ that accounted for $35 \%$ of the explained variance. Subgroup analysis on children seven years of age or younger explained $60 \%$ of the variance in pain scores (MES $=0.47$ ). Adverse events were not reported.

$7 / 8$ studies reported that pain was significantly less in the hypnotized groups compared with control or baseline. Due to methodological limitations the evi dence for the efficacy of hypnosis is inconclusive. Adverse events werenot reported.

Distraction $(\mathrm{SMD}=-0.24 ; 95 \% \mathrm{Cl}-0.45$ to -0.04$)$ and hypnosis $(\mathrm{SMD}=-1.47$; $95 \% \mathrm{Cl}-2.67$ to -0.27 ) significantly reduced self-reported pain compared with control. Combined cognitive-behavioural interventions did not significantly decrease pain. Inconclusive evidence to support other commonly used psychological interventions. Adverse events were not reported.

BMA Bone marrow aspiration; IM Intramuscular; IV Intravenous; LP Lumbar puncture; MES Mean Effect Size; SMD Standardized Mean Difference

to music reduced pain intensity ratings and opioid requirements in general, the magnitude of these benefits was small and, thus, the clinical importance of this reduction was unclear. Furthermore, the authors stated that music therapy should not be considered as a primary method for pain relief.

Kleiber and Harper (17) reviewed the effect of distraction on children's distress behaviour (16 studies) and self-reported pain (10 studies) during medical procedures in 19 studies. Distraction significantly reduced self-reported pain in children across a wide variety of medical procedures. Age (seven years and younger) and type of painful procedure explained a significant amount of the variance. However, other possible moderating variables that should be considered included: variation in distraction intervention (ie, kaleidoscope, package of distraction techniques) and characteristics of the child (ie, temperament). A major limitation of this review was that no data were provided regarding the methodological quality of the studies included in the review.

Uman et al (22) reviewed psychological interventions (ie, cognitive-behavioural strategies) to reduce pain and distress during needle-related procedural pain (ie, immunizations, injections). Twenty-eight trials were included in the review for a total of 1039 participants in the treatment conditions and 951 in the control conditions. Heterogeneity of the samples, poor reporting of the results required for a meta-analysis and overall low methodological quality scores (ie, failure to 
TABLE 3

Systematic reviews with a quality rating less than 5

\begin{tabular}{|c|c|c|}
\hline $\begin{array}{l}\text { Reference, } \\
\text { number of } \\
\text { studies }\end{array}$ & $\begin{array}{c}\text { Quality } \\
\text { score }\end{array}$ & Focus \\
\hline $\begin{array}{l}\text { Rogers and Ostow } \\
2004(20), n=10\end{array}$ & 4 & $\begin{array}{l}\text { EMLA* cream compared with placebo }(n=7) \\
\text { iontophoresis }(n=2) \text { and amethocaine } \\
\text { cream }(n=1) \text { for venipuncture pain }\end{array}$ \\
\hline $\begin{array}{l}\text { Taddio et al } \\
2002 \text { ( } 21), n=8\end{array}$ & 4 & $\begin{array}{l}\text { Lidocaine-prilocaine }\left(E M L A^{*}\right) \text { cream } \\
\text { compared with amethocaine (tetracaine) } \\
\text { gel for procedural pain (ie, intravenous } \\
\text { cannulation, venipuncture and } \\
\text { port-a-cath puncture) }\end{array}$ \\
\hline $\begin{array}{l}\text { Wild and Espie } \\
2004 \text { (23), n=9 }\end{array}$ & 4 & $\begin{array}{l}\text { Hypnosis in pediatric cancer patients } \\
\text { to manage pain associated with } \\
\text { medical procedures (ie, BMA, LP). }\end{array}$ \\
\hline
\end{tabular}

Main results

$\mathrm{EMLA}^{*}$ cream more effective than placebo. Inconclusive evidence regarding

comparative efficacy of $E M L A^{*}$ and iontophoresis. No difference found between

$\mathrm{EMLA}^{*}$ and amethocaine cream. More side effects (erythema, pruritis

and tingling) were observed with iontophoresis compared with EMLA*.

Similar efficacy between lidocaine-prilocaine (60 $\mathrm{min}$ ) and amethocaine (30 $\mathrm{min}$ )

when used as labelled. Amethocaine more efficacious than lidocaine-prilocaine

when applied for the same duration of time (40 min, $60 \mathrm{~min}, 2 \mathrm{~h}$ ). Amethocaine

commonly associated with erythema; lidocaine-prilocaine commonly

associated with blanching.

Inconclusive evidence regarding the efficacy of hypnosis due to

methodological constraints of the primary studies (most failed to have

appropriate control groups). Adverse events were not reported.

${ }^{*}$ AstraZeneca Canada Inc. BMA Bone marrow aspiration; LP Lumbar puncture

report participant withdrawals and method of random assignment) constituted limitations of these studies. Distraction and hypnosis significantly reduced pain in children during needle-related procedures; however, combined cognitivebehavioural interventions did not significantly decrease pain compared with controls. Promising but limited evidence was reported in the use of other psychological strategies including information and preparation, nurse coaching and distraction, parent distraction and positioning, and suggestion with distraction.

Overall, existing evidence supported distraction and hypnosis as interventions that can reduce pain related to needle sticks. However, there is inconclusive evidence regarding the role of music and other psychological strategies, alone or in combination, in decreasing acute procedure-related pain.

\section{DISCUSSION}

The present review sought to critically appraise the research evidence on the effectiveness of pharmacological and nonpharmacological strategies for reducing acute procedurerelated pain in hospitalized children. Only five of eight systematic reviews were of high methodological quality and were therefore included in the comprehensive appraisal. From these high-quality reviews, we found evidence that acute procedurerelated pain can be effectively reduced through the use of selected pharmacological and nonpharmacological strategies. However, there is little published meta-analysis evidence for other commonly used pharmacological and nonpharmacological pain-relieving strategies for acute procedural pain.

A number of rigorous systematic evaluations of pediatric pain-relieving strategies have been performed. However, only one pharmacological intervention was supported for acute procedure-related pain management; the use of amethocaine was found to be superior to EMLA in reducing needle insertion pain (18). Conversely, three of the four reviews of nonpharmacological interventions reported evidence to support effectiveness in reducing acute procedure related pain through distraction $(17,22)$ and hypnosis $(22)$. These findings were unexpected given the plethora of clinical practice guidelines $(8,9,25,26)$ developed that promote the use of a variety of pharmacological interventions in the management of acute procedure-related pain. These include opioids (ie, morphine, fentanyl), anesthetics (topical, local and regional) and adjuvant analgesics (ie, nitrous oxide), as well as a wide variety of nonpharmacological interventions (ie, education, slow rhythmic breathing, relaxation, guided imagery). Many of these commonly used pain management strategies for children have not been rigorously evaluated, and there is limited evidence for their effectiveness. Clinicians are left in a quandary regarding decision-making in their daily practice, and they question the quality of existing practice guidelines, especially beyond the management of needle pain. The reasons for this paucity of RCTs in children's pain management compared with adults may be due to challenges in the measurement of pain (ie, the need to use a variety of age-appropriate pain measures), developmental differences and other contextual factors (ie, severity of illness), important ethical and methodological quality considerations in the conduct of clinical trials, and economic factors (27). High-quality RCTs at multicentre sites remain crucial to elucidate best practices regarding pain management in children.

Despite the identification of suboptimal pain management in hospitalized children for over two decades, regulatory changes and the widespread adoption of minimum care standards for the assessment and management of pain by authorities such as the Joint Commission on Accreditation of Healthcare Organizations (10) and the Canadian Council on Health Service Accreditation (11), children continue to suffer needlessly in pain $(2-4)$. Therefore, further research on the most effective strategies for achieving effective pain control in hospitalized children is imperative. This requires evaluation of methodological quality and attention to methods of translating this knowledge to clinical practice. From the vantage point of evidence-based health care, the small number of systematic reviews on procedural pain management in children identified in the literature, and the methodological limitations that exist within these reviews, highlight the need for more high-quality systematic reviews in the areas of individual and combined pharmacological and nonpharmacological acute pain interventions.

It is now widely acknowledged that the existence of highquality evidence is the first step in improving clinical management of acute procedure-related pain in hospitalized children. 
Translating recommendations resulting from high-quality systematic reviews into practice is a complex interactive process. No longer is research believed to be passively and readily transferred into practice through scholarly publications or presentations (28). Consideration of interactive, multidimensional planned change models that incorporate the interaction among the quality of the evidence, context (ie, organizational culture, leadership and measurement of health care systems) and modes of facilitation (ie, pain resource nurses, pain champions) are required (29).

Systematic reviews have generally not been subjected to quality assessment; therefore, a strength of the present study was the use of a validated rating tool $(13-15)$ to rate the methodological and scientific quality of systematic reviews. It is possible that we may have missed relevant reviews; however, our exhaustive search strategy conducted by two independent raters makes this possibility minimal or unlikely. One of the major limitations of the studies was the wide variation in primary outcome measures in acute pain clinical trials in children. The Pediatric Initiative on Measurement, Methods and Pain Assessment in Clinical Trials statement recommends core outcome measures that should be considered by investigators conducting clinical trials on acute pain in children three to 18 years of age ( $\mathrm{McGrath}$ et al, unpublished study). For acute pain clinical trials, investigators should include measures of pain intensity, global judgment of satisfaction with treatment, symptoms and adverse events, physical recovery, emotional response and economical factors within the cadre of clinical outcomes. In addition, standardization in observation and self-report pain intensity measures across studies is crucial. Two systematic reviews were conducted for both observationalbehavioural pain measures (30) and self-reported pain measures (31) that provide recommendations for measures that should be used in future pharmacological and/or nonpharmacological clinical trials in children.

\section{CONCLUSIONS}

We found evidence that acute procedure-related pain can be effectively reduced through the use of amethocaine, distraction and hypnosis. Currently, there is little evidence of metaanalysis data for other commonly used pharmacological and nonpharmacological pain-relieving strategies for acute procedural pain. Recent epidemiological studies suggest that many hospitalized children are needlessly suffering acute procedurerelated pain despite the implementation of minimum standards of care and best practice guidelines. It is now widely recognized that untreated acute pain has the potential to result in both immediate and long-term consequences. Because pain management continues to be substandard decades after being highlighted as a child health care issue, more primary studies are needed on the efficacy of routinely used pharmacological and nonpharmacological interventions using validated pain tools. In addition, recommendations from high quality RCTs and systematic reviews are integral to both clinicians and policy makers in planning for practice changes that could ultimately contribute to improved patient- and system-related outcomes. Thus, more primary studies, higher quality systematic reviews and effective knowledge translation strategies are required to advance the field and improve clinical outcomes.

ACKNOWLEDGEMENTS: Funding is acknowledged from the Canadian Institutes of Health Research (CTP-79854).
The authors acknowledge the co-investigators of the Canadian Institute for Health Research (CIHR) Team in Children's Pain for providing thoughtful feedback on earlier versions of this manuscript, the Signy Hildur Eaton Chair in Paediatric Nursing Research at The Hospital for Sick Children and the Samuel Lunenfeld Research Summer Student Program for financial support. Jennifer Stinson's work is supported by a CIHR postdoctoral fellowship. The authors acknowledge Elizabeth Uleryk, BA, MLS and Thomasin Adams-Webber, MA, MLS, CAS for assistance with the electronic searches. The authors also thank the reviewers for their helpful comments on an earlier version of this manuscript.

\section{REFERENCES}

1. Ellis JA, Sharp D, Newhook K, Cohen J. Selling comfort: A survey of interventions for needle procedures in a pediatric hospital. Pain Manag Nurs 2004;5:144-52.

2. Helgadóttir HL. Pain management practices in children after surgery. J Pediatr Nurs 2000;15:334-40.

3. Johnston CC, Abbott FV, Gray-Donald K, Jeans ME. A survey of pain in hospitalized patients aged 4-14 years. Clin J Pain 1992;8:154-63

4. Taylor EM, Boyer K, Campbell F. Inpatient pain experience. 11th World Congress on Pain, Sydney, Australia, 2005. Abstract $\# 1700$.

5. Grunau RE, Holsti L, Peters JW. Long-term consequences of pain in human neonates. Semin Fetal Neonatal Med 2006;11:268-75.

6. Schechter NL, Allen DA, Hanson K. Status of pediatric pain control: A comparison of hospital analgesic usage in children and adults. Pediatrics 1986;77:11-5.

7. Anand KJ, Aranda JV, Berde CB, et al. Summary proceedings from the neonatal pain-control group. Pediatrics 2006;117:S9-22.

8. Acute pain management: Operative or medical procedures and trauma, part 2. Agency for Health Care Policy and Research. Clin Pharm 1992;11:391-414.

9. American Academy of Pediatrics. Committee on Psychosocial Aspects of Child and Family Health; Task Force on Pain in Infants, Children, and Adolescents. The assessment and management of acute pain in infants, children, and adolescents. Pediatrics 2001;108:793-7.

10. Berry PH, Dahl JL. The new JCAHO pain standards: Implications for pain management nurses. Pain Manag Nurs 2000;1:3-12.

11. Canadian Council on Health Services Accreditation. <www.cchsa.ca> (Version current at January 28, 2008).

12. Mulrow CD, Cook DJ, Davidoff F. Systematic reviews: Critical links in the great chain of evidence. In: Mulrow CD, Cook D, eds. Systematic Reviews: Synthesis of Best Evidence for Health Care Decisions. Philadelphia: American College of Physicians, 1988:1-4.

13. Oxman AD, Guyatt GH. Validation of an index of the quality of review articles. J Clin Epidemiol 1991;44:1271-8.

14. Oxman AD, Guyatt GH, Singer J, et al. Agreement among reviewers of review articles. J Clin Epidemiol 1991;44:91-8.

15. Jadad AR, McQuay HJ. Meta-analyses to evaluate analgesic interventions: A systematic qualitative review of their methodology. J Clin Epidemiol 1996;49:235-43.

16. Cepeda MS, Carr DB, Lau J, Alvarez H. Music for pain relief (Cochrane Review). In: The Cochrane Library, Issue 2, 2006. Chichester, UK: John Wiley \& Sons, Ltd.

17. Kleiber C, Harper DC. Effects of distraction on children's pain and distress during medical procedures: A meta-analysis. Nurs Res 1999;48:44-9.

18. Lander JA, Weltman BJ, So SS. EMLA and amethocaine for reduction of children's pain associated with needle insertion (Cochrane Review). In: The Cochrane Library, Issue 3, 2006. Chichester, UK: John Wiley \& Sons, Ltd.

19. Richardson J, Smith JE, McCall G, Pilkington K. Hypnosis for procedure-related pain and distress in pediatric cancer patients: A systematic review of effectiveness and methodology related to hypnosis interventions. J Pain Symptom Manage 2006;31:70-84. 
20. Rogers TL, Ostrow CL. The use of EMLA cream to decrease venipuncture pain in children. J Pediatr Nurs 2004;19:33-9.

21. Taddio A, Gurguis MG, Koren G. Lidocaine-prilocaine cream versus tetracaine gel for procedural pain in children. Ann Pharmacother 2002;36:687-92.

22. Uman LS, Chambers CT, McGrath PJ, Kisely S. Psychological interventions for needle-related procedural pain and distress in children and adolescents (Cochrane Review). In: The Cochrane Library, Issue 4, 2006. Chichester, UK: John Wiley \& Sons, Ltd.

23. Wild MR, Espie CA. The efficacy of hypnosis in the reduction of procedural pain and distress in pediatric oncology: A systematic review. J Dev Behav Pediatr 2004;25:207-13.

24. The CONSORT Group. <www.consort-statement.org> (Version current at January 28, 2008).

25. Virani T, et al. Assessment and Management of Pain. Toronto: Registered Nurses' Association of Ontario, 2002:1-174
26. Guideline statement: Management of procedure-related pain in children and adolescents. J Paediatr Child Health 2006;42(Suppl 1):S1-29.

27. Howard RF. Current status of pain management in children. JAMA 2003;290:2464-9.

28. Nutley S, Walter I, Davies HTO. From knowing to doing: A framework for understanding the evidence-into-practice agenda. Evaluation 2003;9:125-48.

29. McCormack B, Kitson A, Harvey G, Rycroft-Malone J, Titchen A, Seers K. Getting evidence into practice: The meaning of 'context'. J Adv Nurs 2002;38:94-104.

30. von Baeyer CL, Spagrud LJ. Systematic review of observational (behavioral) measures of pain for children and adolescents aged 3 to 18 years. Pain 2007;127:140-50.

31. Stinson JN, Kavanagh T, Yamada J, Gill N, Stevens B. Systematic review of the psychometric properties, interpretability and feasibility of self-report pain intensity measures for use in clinical trials in children and adolescents. Pain 2006;125:143-57. 